\title{
Mortality and cancer morbidity among cement workers
}

\author{
K Jakobsson, V Horstmann, $\mathrm{H}$ Welinder
}

\begin{abstract}
Objective-To explore associations between exposure to cement dust and cause specific mortality and tumour morbidity, especially gastrointestinal tumours.

Design-A retrospective cohort study.

Subjects and setting-2400 men, employed for at least 12 months in two Swedish cement factories.

Main outcome measures-Cause specific mortality from death certificates (1952-86). Cancer morbidity from tumour registry information (1958-86). Standardised mortality rates (SMRs; national reference rates) and standardised morbidity incidence rates (SIRs; regional reference rates) were calculated.

Results-An increased risk of colorectal cancer was found $\geqslant 15$ years since the start of employment (SIR 1.6, 95\% confidence interval (95\% CI) 1.1-2.3), mainly due to an increased risk for tumours in the right part of the colon (SIR 2.7, 95\% CI 1·4-4.8), but not in the left part (SIR 1.0, 95\% CI 0.3-2.5). There was a numerical increase of rectal cancer (SIR 1.5, 95\% CI 0.8-2.5). Exposure (duration of blue collar employment)-response relations were found for right sided colon cancer. After $\geqslant 25$ years of cement work, the risk was fourfold (SIR 4.3, 95\% CI 1.7-8.9). There was no excess of stomach cancer or respiratory cancer. Neither total mortality nor cause specific mortality were significantly increased.

Conclusions-Diverging risk patterns for tumours with different localisations within the large bowel were found in the morbidity study. Long term exposure to cement dust was a risk factor for right sided colon cancer. The mortality study did not show this risk.
\end{abstract}

(British Journal of Industrial Medicine 1993;50:264-272)

Department of Occupational and Environmental Medicine, University Hospital, S-221 85 Lund K Jakobsson, V Horstmann, $\mathrm{H}$ Welinder
In a recent case-referent study of gastrointestinal tumours in a Swedish village, ${ }^{1}$ we found that colorectal cancers were associated with Portland cement production; the odds ratio for 25 or more years of blue collar employment was threefold. Further, an association between large bowel tumours and inhalation of various dusts has previously been reported. ${ }^{2}$ An excess of these tumours was also noted among workers exposed to metal dust and abrasives. ${ }^{34}$ Furthermore, in a cohort of asbestos cement orkers, ${ }^{5}$ we have found a surprisingly high risk for colorectal tumours, compared with cohorts of workers in other branches of the asbestos industry. Thus there is some epidemiological evidence that exposure to inorganic dusts may cause colorectal cancer, but more data are needed.

An increased risk for stomach cancer among cement workers has been suggested, ${ }^{6}$ although there are contradictory data. ${ }^{7}$ Several studies have suggested that workers exposed to inorganic dusts have an increased risk of stomach cancer. ${ }^{8-13}$ It has been questioned whether this is due to exposure to dust or to lifestyle factors, ${ }^{14}{ }^{15}$ as several studies have failed to show a relation between dose of dust and risk. ${ }^{16-18}$ In our previous case-referent study, the odds ratio for any blue collar employment in the cement plant was increased among cases with oesophageal or stomach cancer, but short term employment predominated, which makes a causal relation less likely. The numerical excess of upper gastrointestinal tumours among short time employees indicated in our study might instead be attributed to the excess of cancers often seen in short time employees. ${ }^{19}$ Hence, whether causality exists between exposure to inorganic dusts and stomach cancer is still unclear.

In a small study of masons handling cement ${ }^{21}$ lung cancer was seen in excess. Also, an increased risk of lung cancer other than adenocarcinoma was found in a case-control study among workers with prolonged exposure to high levels of concrete dust (possible concomitant exposure to silica), as well as a cluster of lung cancer among lorry drivers exposed to cement and silica. ${ }^{21}$ Also, laryngeal cancers have been associated with exposure to cement dust. ${ }^{22} 23$ In a recent cohort study, however, ${ }^{24}$ no excess risk for 
respiratory cancer was found among cement workers when smoking habits were accounted for. Thus there is some, but weak, support for an association between cement dust and respiratory cancer from previous studies.

Non-malignant respiratory hazards of heavy exposure to inhaled cement dust have long been recognised, ${ }^{25} 26$ but in studies where cement workers were compared with adequate controls, ventilatory decrement has not been shown. ${ }^{27}{ }^{28}$ Further, Danish long term cement workers do not have severe respiratory disease, as reflected by stays in hospital due to chronic obstructive lung disease, more often than other blue collar workers. ${ }^{29}$ Thus there is little reason to expect an increased respiratory mortality among cement workers.

The aim of the present study was to explore associations between exposure to cement dust and cause specific mortality and cancer morbidity, especially gastrointestinal cancer.

\section{Material and methods}

\section{CEMENT PRODUCTION AND PLANT HISTORY}

The cement making process starts with quarrying and crushing of raw marlstone and limestone. The crushing of the raw materials is done in two steps. The first step is always dry. In the second step the material is either ground together with water into a slurry (wet method) or handled dry (dry method).
The silica content is adjusted, if necessary, by addition of sand. The raw mix is heated to $1400^{\circ} \mathrm{C}$ in a rotatory kiln and calcined to clinker. After cooling, the clinker is mixed with gypsum (4\%), and raw limestone $(3 \%)$, and a final grinding process takes place. During the last few years, ferrous sulphate has been added for the reduction of chromium $\left(\mathrm{Cr}^{6+}\right.$ to $\left.\mathrm{Cr}^{3+}\right)$. The finished cement is then stored in silos, packed, and transported from the plant.

Apart from the dusts generated in the cement making process, inhaled contaminants may come from the combustion of fuel and exposures encountered in the maintenance of plant and equipment. As in all high temperature industrial production, asbestos has been used for insulation until the past few years.

Cement production in plant A started in 1919. The annual work force has been around 350 workers. A wet method was used until 1970; the dry method was phased in from 1965. As the quartz content in the marlstone is low, quartz sand has been ground with water and some limestone and added in small amounts (3\%) since'1978. Coal has been used for heating of the kilns except for a few years in the 1940s when peat fuel was used, and between 1960-82 when oil was used.

Plant B started in 1924. The annual work force has been around 400 workers. A wet method was used until 1980; the dry method was phased in from 1970. Small amounts $(3 \%)$ of sandstone, containing quartz,

Table 1 Summarised dust measurements from a cement plant. Total dust concentrations (based on time weighted averages) and number of analysed membrane filters from personal samplings is given

\begin{tabular}{|c|c|c|c|c|c|c|c|c|}
\hline \multirow[b]{3}{*}{ Area/work task } & \multicolumn{8}{|c|}{ Dust concentration } \\
\hline & \multicolumn{2}{|c|}{$1971-75$} & \multicolumn{2}{|c|}{$1976-80$} & \multicolumn{2}{|c|}{$1981-85$} & \multicolumn{2}{|c|}{$1986-$} \\
\hline & No & $\mathrm{mg} / \mathrm{m}^{3}$ & No & $m g / m^{3}$ & No & $m g / m^{3}$ & No & $m g / m^{3}$ \\
\hline \multicolumn{9}{|l|}{ Quarry: } \\
\hline $\begin{array}{l}\text { Drilling } \\
\text { Stone conveyor }\end{array}$ & 9 & $4 \cdot 6$ & - & - & - & - & - & - \\
\hline $\begin{array}{l}\text { Stone conveyor } \\
\text { Stone crushing }\end{array}$ & 17 & 22 & 11 & 6.9 & 一 & - & - & $\overline{0}$ \\
\hline $\begin{array}{l}\text { Stone crushing } \\
\text { Stone storage; cleaning }\end{array}$ & 14 & 13 & 20 & 11 & - & - & 2 & 23 \\
\hline $\begin{array}{l}\text { Stone storage; cleaning } \\
\text { Raw mill area: }\end{array}$ & 4 & 21 & 6 & 25 & - & - & - & - \\
\hline \multicolumn{9}{|l|}{ Raw mill area: } \\
\hline $\begin{array}{l}\text { Raw mill operator: } \\
\text { Cleaning }\end{array}$ & 15 & 12 & 11 & $4 \cdot 6$ & - & - & 2 & 1.8 \\
\hline $\begin{array}{l}\text { Cleaning } \\
\text { Sand slurry operator }\end{array}$ & 11 & 16 & 11 & 11 & - & - & - & - \\
\hline $\begin{array}{l}\text { Sand slurry operator } \\
\text { Cyclone tower: }\end{array}$ & 7 & $3 \cdot 3$ & - & - & - & - & - & - \\
\hline \multicolumn{8}{|l|}{ Cyclone tower: } & \\
\hline $\begin{array}{l}\text { Cleaning } \\
\text { Kiln and clinker area: }\end{array}$ & 12 & 150 & 13 & 41 & 16 & 17 & 4 & $4 \cdot 6$ \\
\hline \multicolumn{9}{|l|}{ Kiln and clinker area: } \\
\hline $\begin{array}{l}\text { Kiln; cleaning } \\
\text { Clinker; transport }\end{array}$ & $\begin{array}{l}11 \\
11\end{array}$ & $\begin{array}{l}20 \\
3 \cdot 8\end{array}$ & E & - & 二 & 二 & $\overline{-}$ & - \\
\hline $\begin{array}{l}\text { Clinker; transport } \\
\text { Clinker; cleaning }\end{array}$ & 4 & 40 & 6 & $\overline{33}$ & $\overline{22}$ & $\overline{22}$ & 4 & $4 \cdot 1$ \\
\hline \multicolumn{9}{|l|}{ Cement mill area: } \\
\hline Operator & 10 & 12 & 10 & $5 \cdot 8$ & 7 & 3.9 & - & - \\
\hline Cleaning & 19 & 25 & 18 & $5 \cdot 0$ & 17 & $8 \cdot 3$ & 4 & $9 \cdot 4$ \\
\hline Cement silo cleaning & 12 & 530 & - & - & - & - & - & - \\
\hline \multicolumn{8}{|l|}{ Packing area: } & - \\
\hline Bag packing & $\begin{array}{r}35 \\
4\end{array}$ & $\begin{array}{r}16 \\
130\end{array}$ & $\begin{array}{l}25 \\
26\end{array}$ & $\begin{array}{c}10 \\
8 \cdot 2\end{array}$ & 14 & 17 & $\overline{4}$ & 3.6 \\
\hline $\begin{array}{l}\text { Cleaning } \\
\text { Bulk loading }\end{array}$ & $\begin{array}{l}4 \\
6\end{array}$ & $7 \cdot 3$ & - & 5.0 & - & - & - & - \\
\hline \multicolumn{9}{|l|}{ Service and repair: } \\
\hline Maintenance jobs & 12 & 14 & 一 & $\overline{-}$ & 二 & 二 & $\bar{Z}$ & E \\
\hline Filter service and repair & 4 & 790 & $\overline{-}$ & 二 & 二 & $\overline{-}$ & $\bar{z}$ & $\overline{-}$ \\
\hline Repair & 22 & 25 & - & - & & & & \\
\hline
\end{tabular}


was crushed and added until 1979 , then replaced by sand. The kilns were heated with coal, except during the period 1955-84 when oil was used.

As well as the production of ordinary Portland cement, small amounts of a coloured masonry cement were produced between 1963 and 1981. Oxides of iron, chromium, and titanium were used as pigments. Only a handful of men had been engaged in the mixing and bagging of this product, which took place in a separate building.

\section{Exposure levels}

The work environment in both plants did not change appreciably until the 1960s when new cement ovens were installed and automatic process control was introduced. Also, some very dusty work tasks then disappeared. The ventilation inside the factory did not immediately parallel an increased production, but improved gradually during the 1970s.

The transportation and packing of the cement were very dusty operations until the late 1950s, and involved screw conveyors, open pack machines, wood bins, or cloth bags. Subsequently the cement has been handled in closed systems and packed in bulk or in paper bags, reducing dust concentrations substantially.

In plant $B$ a survey of dust concentrations was performed in 1953. In the stone crushing area particle counts (midget impinger) ranged between 0.4 and $2 \times 10^{3}$ particles $/ \mathrm{cm}^{3}$ and in the packing area, $3-8 \times 10^{3}$ particles $/ \mathrm{cm}^{3}$. In 1971 and 1973 surveys of the plant with extensive stationary and personal membrane filter samplings were performed. Thereafter, several samplings from areas and jobs of special concern have been performed (table 1). Total dust measurements during the early 1970 s were generally lower than $20 \mathrm{mg} / \mathrm{m}^{3}$; later on below $10 \mathrm{mg} / \mathrm{m}^{3}$. During cleaning and in special situations, dust concentrations above $100 \mathrm{mg} / \mathrm{m}^{3}$ have been found. Some kind of protective masks may, however, have been used during these operations.

From plant $\mathrm{A}$, there are less data on dust concentrations. The earliest dust measurements available are from 1976. In 1979 measurements to assess the exposure to quartz were made. Later on, more selective samplings from areas and jobs of special concern have been made. Total dust concentrations were generally lower than $10 \mathrm{mg} / \mathrm{m}^{3}$ but in some instances up to $25 \mathrm{mg} / \mathrm{m}^{3}$.

The quartz content in the dust was generally $<5 \%$. In areas where the raw materials are handled, respirable quartz concentrations are generally assumed to be less than $0.1 \mathrm{mg} / \mathrm{m}^{3}$ if the total dust concentration is below $10 \mathrm{mg} / \mathrm{m}^{3}$. Workers handling clinker and finished cement are exposed to substantially lower quartz concentrations. There have not been any cases of silicosis in the cement plants.

In 1980, chromium and other trace metals were analysed in samples from raw materials, clinker, and cement in plant $\mathrm{A}$. The chromium concentrations ranged from 49 to 389 (median 58) $\mathrm{mg} / \mathrm{kg}$. In the finished cement concentration was $40 \mathrm{mg} / \mathrm{kg}$. The cadmium concentrations were $<0.2 \mathrm{mg} / \mathrm{kg}$, with a few exceptions. Only a few analyses of chromium in the raw materials and finished cement are available from plant $B$. The marlstone contained $16 \mathrm{mg} \mathrm{Cr} / \mathrm{kg}$ and the cement $90 \mathrm{mg} / \mathrm{kg}\left(20 \mathrm{mg} \mathrm{Cr}^{6+} / \mathrm{kg}\right)$.

\section{COHORT}

Company records from both plants were regarded as complete from the late 1940s. The cohort was defined as all men still employed on 1 January 1952 or employed since then, and with a total employment time of 12 months or more. Vital status was determined until 31 December 1986. There were 1205 men in plant $\mathrm{A}$, and only two of them $(0.2 \%)$ were lost to follow up. In plant B, there were 1195 men, of whom seven $(0 \cdot 6 \%)$ were lost.

MORTALITY, CAUSE OF DEATH, AND TUMOUR MORBIDITY Information on cause of death from 1952 to 1986 was obtained from Statistics Sweden. The death certificates were coded, according to the 8th revision of the International Classification of Diseases (ICD-8), by Statistics Sweden, which is responsible for the coding of all Swedish death certificates. In $30 \%$ of the deceased men from plant $A$ and in $26 \%$ from plant $B$, death certificates were based on clinical or forensic necropsy. In total, there were 495 deaths during 52177 person-years.

Information on at most two tumours, coded according to ICD-7, and diagnosed from 1958 to 1986, was obtained from the National Swedish Tumour Registry. Histological or cytological examinations had been performed in $89 \%$ of the tumours in workers from plant A and $93 \%$ from plant B, according to registry information. In total, 162 malignant tumours were found during 46133 person-years.

\section{RISK ESTIMATES}

Expected mortality for the period 1952-86 was calculated using cause, calendar year, and five year age group specific death rates for males in Sweden. These rates were calculated from death and population counts obtained from Statistics Sweden. Similarly, yearly cancer morbidity rates during the period 1958-86 were obtained from the National Swedish Tumour Registry. National rates as well as country rates were available. Date of diagnosis of a tumour, date of death, or emigration, or the 85th birthday, were used as individual endpoints.

\section{EXPOSURE INDICES}

All job and area codes mentioned in the company records were scrutinised by two or three long term 
Table 2 Assumed exposure intensity levels (arbitrary units) during different periods in two cement plants

\begin{tabular}{llll}
\hline & \multicolumn{2}{l}{ Period } & \\
\cline { 2 - 4 } Intensity & -1964 & $1965-79$ & 1980 \\
\hline No & 0 & 0 & 0 \\
Slight & 1 & 1 & $0 \cdot 4$ \\
Medium & 5 & $2 \cdot 5$ & 1 \\
High & 10 & 5 & 2 \\
\hline
\end{tabular}

foremen at each plant. Together, they scored the intensity of dust exposure for each job category as no (white collar work), slight (for example, workers in supply depots, custodians, workers in the laboratory, and in the workshops), medium (for example, repair and maintenance work partly in the workshops and partly in the production area; most quarry workers), or high (most workers in the production area and in packing operations). This coding was done independently at each plant. For comparable job types, the classifications turned out to be consistent.

For each worker, job histories were extracted from the plant records. Cumulated employment time in blue collar work was determined. Thus for a man who had been both a blue collar and a white collar worker, the employment periods as a white collar worker were disregarded. For a few men, the type of work during a certain period could not be determined and this employment period was disregarded.

The highest exposure intensity category that a worker reached was used as one index of exposure. This measure was highly correlated with intensity of exposure category at the first job assignment and also with the category for the job assignment with the longest duration.

Based on interviews with plant personnel, information on production history, dust measurements, and a general knowledge on industrial exposure to dust, an exposure matrix was constructed (table 2).
Each job category was assigned an arbitrary dust intensity score, which varied with time. Three different periods (before 1965, 1965-79, 1980 and after) were considered. Individual cumulated dose estimates were constructed by multiplying the arbitrary dust intensity score (from the matrix) by the time spent in each job held. Ten units of accumulated dose could therefore represent, for example, exposure for 10 years in a job with a dose rating of one, or one year in a job with a rating of 10. The average total dust concentration for a job with a rating of 5 was assumed to be in the range 10-20 $\mathrm{mg} / \mathrm{m}^{3}$. If there was a lack of information concerning any employment period, the exposure during that period was set to zero, thus underestimating the dose of the worker.

\section{ANALYSES}

Cause specific standardised mortality rates (SMRs) and incidence rates (SIRs) and $95 \%$ confidence intervals ( $95 \% \mathrm{CIs}$ ) were calculated according to the Poisson distribution. Expected values for mortality were calculated from national rates; morbidity rates were based on regional (county) data, if not national rates are explicitly stated. The term significant $(p<0.05)$ corresponds to a lower limit of $95 \%$ CI for SMR or SIR greater than 1.00.

When time since start of employment, duration of employment, and cumulated dose were considered, exposure-response relations were assessed by analyses of SIRs over strata based on the individual cumulated time or dose. Thus, each worker contributed person-years successively to each stratum. ${ }^{30} 31$

\section{Results}

In the total cohort, neither overall mortality, nor cause specific non-malignant mortality differed significantly from national rates (table 3 ). The pattern

Table 3 Mortality and specific causes of death 1952-86 in men employed for at least 12 months in two cement plants

\begin{tabular}{|c|c|c|c|c|c|c|c|c|c|}
\hline \multirow[b]{2}{*}{ Cause of death } & \multirow[b]{2}{*}{$I C D-8$} & \multicolumn{4}{|c|}{ All subjects $(n=2391)$} & \multicolumn{4}{|c|}{$\geqslant 15$ years since start of employment $(n=1789)$} \\
\hline & & $O$ & $E$ & $S M R$ & $(95 \% C I)$ & $O$ & $\boldsymbol{E}$ & $S M R$ & $(95 \% C I)$ \\
\hline
\end{tabular}

$\mathrm{O}=$ Observed deaths; $\mathrm{E}=$ Expected deaths (from national reference rates). 
Table 4 Cancer morbidity 1958-86 in men employed for at least 12 months in two cement plants

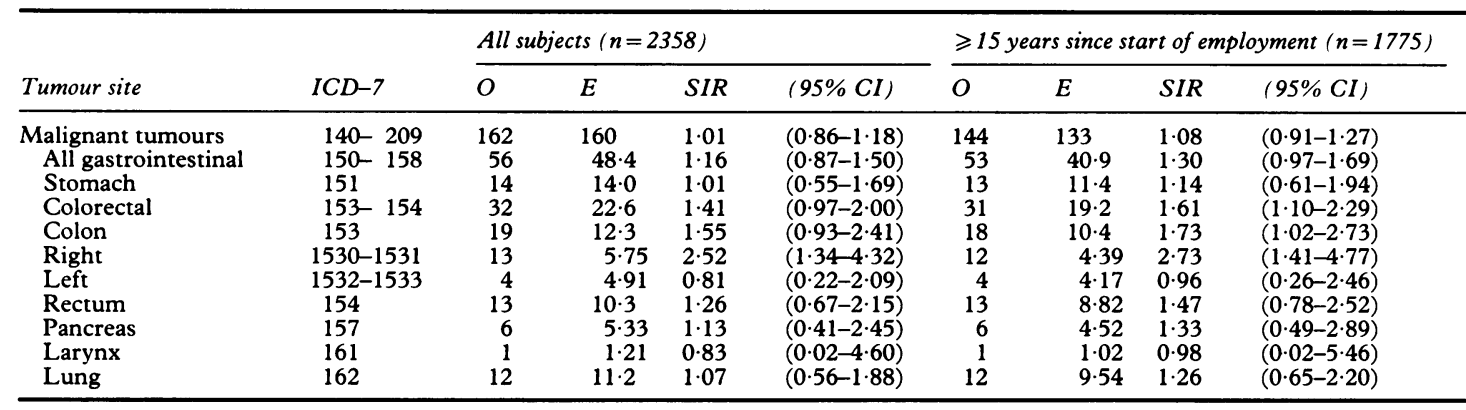

$\mathrm{E}$ from regional reference rates.

was the same in both plants, apart from a slight increase of violent deaths in plant B. Altogether 23 observed $v 27$ expected deaths occurred from nonmalignant respiratory diseases. Neither total malignant mortality nor mortality from specific malignancies differed significantly from the expected national incidence (plants combined). Most of the cancer deaths occurred 15 years or more after start of employment when there were 16 observed $v 14$ expected deaths from colorectal cancer and 11 observed $v 17$ expected deaths from lung cancer.

Total tumour morbidity and all gastrointestinal tumour morbidity did not differ significantly from the expected incidences (table 4). Neither respiratory cancers nor cancers at other sites outside the gastrointestinal system (not in table), were in excess. For workers in the two plants combined after at least 15 years since the start of employment there was a significant increase of colon cancer (in plant A, six observed, SIR 1.31; in plant B, 12 observed, SIR $2 \cdot 06)$. The SIR for rectal cancer was non-significantly increased (in plant A, eight observed, SIR 1.58, in plant B, five observed, SIR 1.33). Among blue collar workers, all cases of colorectal cancer occurred at least 15 years after the start of employment. With increasing duration of blue collar employment, there was no clear trend of rising SIRs for all colorectal morbidity; there was a significant twofold excess (SIR $1 \cdot 84,95 \%$ CI $1 \cdot 12-2 \cdot 84$ ) of these tumours, however, after 15 years or more of blue collar employment.

Particularly for the colon there was a significant increase of cancers in the right part, but not in the left part. For cancer in the right part of the colon, the relative risk increased with increasing time since the start of blue collar employment and with increasing duration of blue collar employment; this was especially so in plant B (table 5). After $\geqslant 25$ years of blue collar employment, the relative risk was fourfold (SIR $4.31,95 \%$ CI $1 \cdot 73-8 \cdot 87$ ). There was no doseresponse relation using exposure intensity category as an exposure index (not taking duration of exposure and estimated changes in dust concentrations into account). With cumulated dose as another index of exposure it was evident that most excess right sided color cancers were localised in the highest dose category ( $\geqslant 100$ units; SIR 4.37, 95\% CI 1·8-9.0). In plant B SIRs increased with increasing cumulated dose; in plant $A$ there was no such trend. When each worker was classified as to the duration or dose that had been achieved 15 years earlier (lag) the pattern did not change but the point estimates were somewhat higher.

For cancer in the left part of the colon (not in table) there was a discrepancy between plants, as there were no left sided colon cancers in plant $A$; furthermore, the four left sided colon cancers found in plant $B$ were evenly localised across all exposure strata. Rectal cancers (11 observed $v 7.9$ expected among blue collar workers) were found in both plants, localised in all exposure strata without any trend of increasing relative risk with increasing duration of employment or cumulated dose (not in table).

For cancers of the stomach and pancreas among blue collar workers, the same types of analyses as for colorectal cancers were performed (not in tables). Overall, there were no increases and no significant dose-response patterns. Also, discrepancies existed between the plants. In plant $B$, more stomach cancers than expected were allocated to categories with long and heavy exposure, whereas in plant $\mathrm{A}$, by contrast, an overall deficit and a deficit in the longer exposure/ time since start of exposure categories was found. There was a numerical excess of cancers of the pancreas in plant A (six observed, SIR $2 \cdot 67,95 \%$ CI $0 \cdot 98-5 \cdot 8$ ), allocated to categories with long and heavy exposure; no cases were found in plant $B$.

Review of the job histories of cases with cancer of the colon, rectum, and pancreas did not show any clustering of specific job titles. In plant $B$ five of the nine men with stomach cancer had been working in 
Table 5 Relations between time since start of employment and risk, duration of blue-collar employment and risk, and cumulated dose and risk for right-sided colon cancer (ICD 1530-1531) in the cohorts of cement workers, employed for at least 12 months in two cement plants

\begin{tabular}{|c|c|c|c|c|c|}
\hline Index & Plant & Person-years & $O$ & $E$ & $S I R(95 \% C I)$ \\
\hline \multicolumn{6}{|c|}{ Years since start of blue collar employment: } \\
\hline \multirow[t]{3}{*}{$<15$} & A & 9168 & 0 & 0.29 & $0.00(0.00-12.7)$ \\
\hline & & 9122 & 0 & 0.31 & $0.00(0.00-12.0)$ \\
\hline & $\bar{A}+\mathbf{B}$ & 18290 & 0 & 0.59 & $0.00(0.00-6.18)$ \\
\hline \multirow[t]{3}{*}{$15-24$} & & 5553 & 1 & 0.56 & $1.78(0.00-9.90)$ \\
\hline & & 5102 & 1 & 0.52 & $1.93(0.05-10.7)$ \\
\hline & $\mathbf{A}+\mathbf{B}$ & 10655 & 2 & 1.08 & $1.85(0.22-6 \cdot 68)$ \\
\hline \multirow[t]{3}{*}{$\geqslant 25$} & & 5245 & 4 & 1.39 & $2.88(0.78-7.37)$ \\
\hline & & 4530 & 6 & 1.34 & $4.49(1.65-9.77)$ \\
\hline & $A+B$ & 9775 & 10 & $2 \cdot 73$ & $3.67(1.76-6.74)$ \\
\hline \multicolumn{6}{|c|}{ Years of blue collar employment: ${ }^{\star}$} \\
\hline \multirow[t]{3}{*}{$0-14$} & $\mathbf{A}$ & 6154 & 3 & 0.74 & $4.00(0.83-11 \cdot 7)$ \\
\hline & & 5340 & 0 & 0.67 & $0.00(0.80-5.47)$ \\
\hline & $\mathbf{A}+\mathbf{B}$ & 11494 & 3 & 1.43 & $2 \cdot 10(0.43-6 \cdot 15)$ \\
\hline \multirow[t]{3}{*}{$15-24$} & & 2649 & 0 & 0.50 & $0.00(0.00-7.37)$ \\
\hline & & 2136 & 2 & 0.39 & $5 \cdot 17(0.63-18 \cdot 7)$ \\
\hline & $\mathbf{A}+\mathbf{B}$ & 4785 & 2 & 0.89 & $2 \cdot 25(0 \cdot 27-8 \cdot 14)$ \\
\hline \multirow[t]{3}{*}{$\geqslant 25$} & & 2430 & 2 & 0.79 & $2.55(0.31-9.20)$ \\
\hline & & 2432 & 5 & 0.84 & $5.95(1.93-13.9)$ \\
\hline & $A+B$ & 4862 & 7 & 1.63 & $4.31(1.73-8.87)$ \\
\hline \multicolumn{6}{|c|}{ Cumulated dose ${ }^{\star}$} \\
\hline \multirow[t]{3}{*}{$0.1-9$ units } & A & 2086 & 2 & $0 \cdot 12$ & $17 \cdot 39(2 \cdot 11-62 \cdot 8)$ \\
\hline & & 1655 & 0 & $0 \cdot 11$ & $0.00(0.00-33.7)$ \\
\hline & $\mathbf{A}+\mathbf{B}$ & 3740 & 2 & 0.22 & $8.91(1.08-32.2)$ \\
\hline \multirow[t]{3}{*}{ 10-99 units } & & 5348 & 1 & 0.87 & $1.15(0.03-6.39)$ \\
\hline & & 4777 & 2 & $0 \cdot 70$ & $2.85(0.35-10.3)$ \\
\hline & $\mathbf{A}+\mathbf{B}$ & 10125 & 3 & 1.57 & $1.91(0.39-5.58)$ \\
\hline \multirow{3}{*}{$\geqslant 100$ units } & & 3800 & 2 & 1.05 & $1.91(0.23-6.88)$ \\
\hline & & 3478 & 5 & 1.09 & $4.58(1.49-10.7)$ \\
\hline & $\mathbf{A}+\mathbf{B}$ & 7278 & 7 & $2 \cdot 14$ & $3.27(1.31-6.74)$ \\
\hline
\end{tabular}

^Observation period starts 15 years after first employment. $\mathrm{E}$ from regional reference rates.

the quarry; in plant A one out of five. All men with colorectal cancer had started their employment before 1960 .

\section{CHARACTERISTICS OF CASES OF GASTROINTESTINAL CANCER}

All cancers of the colon, rectum, and pancreas (morbidity) from plant $A$ were verified by histology or cytology, as were three of five stomach cancers. In plant B, all colon cancers, five of six rectal cancers, and seven of eight stomach cancers were verified in this way. Only adenocarcinomas were found. Radiographic investigations had been performed in the other cases.

Of the 19 men with colon cancer, 11 were deceased. Only six of them had had colon cancer noted as the cause of death; furthermore, for none of them was the subsite stated in the death certificate the same as in the tumour registry notification.

\section{Discussion}

In our previous community based case referent study $^{1}$ an excess of colorectal cancers among long term cement workers (from plant A) was found. This finding was corroborated in the present study, combining results from two cement plants with similar production history-the mentioned plant $A$, and plant B located in a different region in Sweden.
It has, however, been pointed out ${ }^{32}$ that colon cancers-or even cancer in different subsites of the colon-should be considered different from each other and from rectal cancer. ${ }^{233}$ Diverging international incidence patterns over time, diverging sex, age, and social class distributions, and different patterns for known risk factors, are the epidemiological basis for the arguments in favour of such a separation. Differences have been noted in the biological properties of proximal and distal segments of normal colonic epithelium, and in the pathological, cytogenetic, and molecular features of proximal and distal colorectal cancer (reviewed in ${ }^{33}$ ). Evidence of physiological variations within the large bowel is also accumulating. ${ }^{34}$ Thus these biological differencesmay determinedifferencesin susceptibility to environmental agents within the large bowel. In a tumour registry based case-control study of colon cancer, analyses by anatomic subsite showed that excess risk for an occupational group was usually confined to a single subsite, which further suggests some specificity of effect. ${ }^{35}$

In the present study, the excess of colorectal cancer was mainly due to an increase of cancer in the ascendent and transverse parts of the colon. The risk was fourfold after $\geqslant 25$ years of employment. It should be stressed that we were able to find this increased risk only when we used cancer morbidity 
data. The mortality study was not sensitive enough, due to a low mortality from colon cancer (one third), and because death certificate notes on cancer subsite were not accurate enough.

What is the evidence for a causal relation between cement dust and cancer in the right part of the colon? In answering this question, criteria such as time relation, dose-response, consistency, strength of the association, and biological plausibility should be considered. For cancer of the right colon, there is a relation with time since the start of exposure that is consistent between two plants from different regions of Sweden, as is the overall excess.

Dose-response relations were evaluated with duration of blue collar employment as a crude measure of exposure. An increase in relative risk with increasing duration of blue collar employment was evident. For cumulated dose there was a significant threefold risk in the highest dose category, corresponding to roughly $\geqslant 200-400 \mathrm{mg} / \mathrm{m}^{3} \times$ years.

When duration of blue collar employment was used as an exposure estimate, changes in exposure intensity over time were not taken into account. Analyses were also made with a lag period of 15 years, however, and the patterns were the same as in the analyses without lagged exposure, but the point estimates were in general somewhat higher. When applying a lag period of 15 years, the impact of the changes in the working environment that began in the 1960s with gradual improvements during the 1970s and later on were less obvious, as the end of follow up was 1986. Thus lagged duration is presumably a good exposure index. A dose-response pattern was not seen with cumulated dose as an exposure index. The cumulated dose is probably subject to a higher degree of misclassification than is the duration of blue collar employment. Firstly, it is based on job histories noted in the plant records and these may be inaccurate. Especially, changes in job tasks within the blue collar area may not be registered, whereas transitions between blue collar work and white collar work were probably more carefully noted. Secondly, the cumulated dose is based on two different scorings-the job-category score and the arbitary dust intensity score, neither of which is particularly accurate. The misclassification resulting from these two problems is non-differential and would tend to make true dose-response relations less clearcut.

No cases of colorectal cancer were found among those who had started their employment after 1960. This does not, of course, imply that exposure after 1960 gives a neglible risk. This subgroup of the cohort is still young, and only $0 \cdot 2$ cases of cancer in the right colon were expected.

The magnitude of a relative risk might be biased by an improper choice of reference population. Our industrial population had to be compared with general population rates. Blue collar workers have a lower risk for right sided and left sided colon cancer than the entire working population. ${ }^{36}{ }^{37}$ Thus the use of any general population underestimates the risk for colon cancer. Farmers have an even lower risk of colon cancer, ${ }^{36}$ which would lead to bias in the opposite direction of the risk if the reference population has a high proportion of farmers. A problem is that the proportions of blue collar workers and farmers differ in the two counties surrounding the present factories. This may explain why the incidence of gastrointestinal cancer varies between these regions (in county $\mathbf{A}$ there was a lower colon cancer morbidity and a higher rectal cancer morbidity compared with both county $B$ and the country). Also, there are other possibilities, such as variations in dietary habits, which are known to affect the risk. ${ }^{32}$ The most reasonable solution to the problem of choosing a relevant reference population is to use the respective county rates, as we have done. Even if the magnitude of the relative risk for colon and rectal cancer might be biased by use of improper reference rates, time-response and dose-response patterns ought not to be affected. It must, however, be kept in mind that for all exposure categories, there is a substantial uncertainty with the point estimates of the relative risk in each time or dose interval, due to small numbers. Thus the data are consistent with a variety of exposure-response patterns.

A raised risk for colorectal tumours in cement workers has not been previously described, except in our earlier case-referent study. In that study, colorectal cancers combined were examined. A reanalysis of this study showed, however, that the risk (work in plant A) was confined to cancers in the right part of the colon and in the rectum. It should be noted that the highest point estimates and the clearest dose-response relations for right-sided colon cancers in the present study were seen in plant B-that is, not around the plant of the original observation in the case-referent study. Interestingly, in a registry based mortality study of cement workers, a non-significantly raised SMR of 1.88 for rectal tumours was noted. ${ }^{6}$

There are few studies of workers exposed to inorganic dusts that report results for separate sites within the large bowel. A risk of colorectal cancer associated with cement is indicated by the fact that in a cohort of asbestos-cement workers, we have found a surprisingly high risk for colorectal tumours compared with reports of cohorts of workers in other areas of the asbestos industry. ${ }^{5}$ Also, some reports exist of an increased risk of colorectal cancer associated with exposure to various other inorganic dusts. In a cohort of metal grinders, an excess of colorectal cancer was ascribed to exposure to dust from metals and abrasives. ${ }^{3}$ In some studies of metal workers (also exposed to cutting oils) rectal cancers, but not colon cancers were reported to be in 
excess. ${ }^{38} 39$ By contrast, among pattern and model makers exposed to wood and metal dusts, colon but not rectal cancers were in excess. ${ }^{40}$ In a case-referent study of bowel cancer morbidity in young urban men, tumours in the rectum and to a lesser degree the sigmoid colon, were associated with dusty jobs. ${ }^{2}$ Metal and wood dust conveyed the greatest risk in both the rectum and the adjacent sigmoid. This is by contrast with our finding of an increased risk for cancer in the ascendent and transverse part of the colon; however, in our study the bowel cancers occurred in elderly men in non-urban areas, which may reflect other concomitant risk factors.

We could not show a consistent or dose related risk for stomach cancer among the cement workers. This is in accordance with the findings from another cohort study of workers from six cement plants. ${ }^{7}$

Is there any biological reason why inorganic dust should cause bowel cancer? Knowledge is virtually absent. Undoubtedly, inhaled dusts can reach the gastrointestinal tract via lung clearance and mucociliary transport mechanisms, and subsequent swallowing. This should be especially true for inert dusts, which to a small degree cause lung and airway disease with subsequent disturbance of these mechanisms. The present cement workers had no increased risk for non-malignant respiratory disease; also, other studies indicate that there is not an increased risk for respiratory diseases among cement workers. ${ }^{27-29}$

The normal diet contains a large number of carcinogenic compounds and their precursors ${ }^{41}$ and their concentration is highest in the proximal colon. Also, secondary bile acids, which are mutagenic or cocarcinogenic, ${ }^{42}$ have the greatest impact on the cancer process in the right colon. ${ }^{43}$ In the proximal parts of the colon, retrograde peristalsis churns and mixes the liquid stool, ${ }^{34}$ the traffic in and out of the lumen is heavy, and the transit time is comparatively long. By contrast, the distal parts of the colon have a storage function. Thus there is a good possibility that the cement dust gets in close contact with the mucosa in the proximal colon. The ingested inorganic dust particles may have a non-specific irritating effect on the mucosa, thereby decreasing its normal protective mechanisms and enhancing the effects of other carcinogens.

We thank the staff at the cement factories and their company health services for kind collaboration. Christina Paradis-Johansson, Katarina Sjöland, and Maria Wikman assisted in the data collection. Ulf Strömberg assisted in the statistical analyses and Staffan Skerfving gave valuable comments on the manuscript. The study was financially supported from the Swedish Work Environment Fund, the Faculty of Medicine, University of Lund, and Smålands nation, Lund.
1 Jakobsson K, Attewell R, Hultgren B, Sjöland K. Gastrointestinal cancer among cement workers: a case-referent study. Int Arch Occup Health 1990;62:337-40.

2 Peters RK, Garabrant DH, Yu MC, Mack TM. A case-control study of occupational and dietary factors in colorectal cancer in young men by subsite. Cancer Res 1989;49:5459-68.

3 Spiegelman D, Wegman DH. Occupation-related risks for colorectal cancer. J Natl Cancer Inst 1985;75:813-21.

4 Svensson BG, Englander V, Åkesson B, Attewell R, Skerfving S, Ericsson $\AA$, Möller T. Deaths and tumours among workers grinding stainless steel. Am J Ind Med 1989;15:51-9.

5 Albin M, Jakobsson K, Attewell R, Johansson L, Welinder H. Mortality and cancer morbidity in cohorts of asbestos cement workers and referents. Br J Ind Med 1990;47:602-10.

6 McDowall ME. A mortality study of cement workers. $\mathrm{Br} J$ Ind Med 1984;41:179-82.

7 Amandus HE. Mortality from stomach cancer in United States cement plant and quarry workers, 1950-80. Br J Ind Med 1986;43:526-8.

8 Rockette HE. Cause-specific mortality of coal miners. J Occup Med 1977;19:795-801.

9 Office of Population Censuses and Surveys. Registrar General's decennial supplement-occupational mortality 1970-2. London: HMSO, 1978.

10 Craven JL, Baum M, West RR. Variations in gastric cancer incidence in south Wales. Clinical Oncology 1979;5:34-51.

11 Fox AJ, Goldblatt P, Kinlen LJ. A study of the mortality of cornish tin miners. Br J Ind Med 1981;38:378-80.

12 Siemiatycki J, Dewar R, Lakhani R, Nadon L, Richardson L, Gérin $M$. Cancer risks associated with 10 inorganic dusts: results from a case-control study in Montréal. Am J Ind Med 1989;16:547-67.

13 Wu-Williams AH, Yu MC, Mack TM. Life-style, workplace, and stomach cancer by subsite in young men of Los Angeles county. Cancer Res 1990;50:2569-76.

14 Stukonis M, Doll R. Gastric cancer in man and physical activity at work. Int J Cancer 1969;4:248-54.

15 Creagan ET, Hoover RN, Fraumeni JF Jr. Mortality from stomach cancer in coal mining regions. Arch Environ Health 1974;28:28-30.

16 Weinberg GB, Kuller LH, Stehr PA. A case-control study of stomach cancer in a coal mining region of Pennsylvania. Cancer 1985;56:703-13

17 Atuhaire LK, Campbell MJ, Cochrane AL, Jones M. Gastric cancer in a south Wales valley. Br J Ind Med 1986;43:350-2.

18 Swaen GMH, Aerdts WHM, Slangen JJM. Gastric cancer in coalminers: final report. $\mathrm{Br} J$ Ind $\mathrm{Med}$ 1987;44:777-9.

19 Gilbert ES. Some confounding factors in the study of mortality and occupational exposures. Am J Epidemiol 1982;116: 177-88.

20 McDonald AD, Fry JS, Woolley AJ, McDonald JC. Dust exposure and mortality in an American chrysotile asbestos friction products plant. $\mathrm{Br} J$ Ind Med 1984;41:151-7.

21 Rafnsson V, Johannesdottir SG. Mortality among masons in Iceland. $B r J$ Ind Med 1986;43:522-5.

22 Olsen J, Sabroe S. Occupational causes of laryngeal cancer. $J$ Epidemiol Community Health 1984;38:117-21.

23 Maier H, Dietz A, Zielinski D, Jünemann KH, Heller WD. Riskofactoren bei Plattenepithelkarzinomen der Mundhöhle, des oropharynx, des Hypopharỹnx und des Larynx. Dtsch Med Wochenschr 1990;115:843-50.

24 Kalacic I. Early detection of expiratory airflow obstruction in cement workers. Arch Environ Health 1974;29:147-9.

25 Vestbo J, Knudson KM, Raffn E, Korsgaard B, Vejlø Rasmussen F. Exposure to cement dust at a Portland cement factory and the risk of cancer. BrJ Ind Med 1991;48:803-7.

26 Oleru UG. Pulmonary function and symptoms of Nigerian workers exposed to cement dust. Environmental Research 1984;33:379-85.

27 Rasmussen FV, Borchsenius L, Holstein B, Sølvsteen P. Lung function and long-term exposure to cement dust. Scandinavian Journal of Respiratory Diseases 1977;58:252-64.

28 Abrons HL, Petersen MR, Sanderson WT, Engelberg AL, Harber P. Symptoms, ventilatory function, and environmental exposures in Portland cement workers. Br J Ind Med 1988;45:368-375.

29 Vestbo J, Rasmussen F. Long-term exposure to cement dust and later hospitalization due to respiratory disease. Int Arch Occup Environ Health 1990;62:217-20.

30 Breslow NE, Lubin JH, Marek P, Langholtz B. Multiplicative models and cohort analysis. Journal of the American Statistical Association 1983;78:1-12.

31 Swaen GMH, Volovics A. Investigating dose-response relations 
in occupational mortality studies: something to keep in mind. Br J Ind Med 1987;44:642-4.

32 Weisburger JH, Wynder EL, Horn CL. Nutritional factors and etiologic mechanisms in the causation of gastrointestinal cancers. Cancer 1982;50:2541-9.

33 Bufill JA. Colorectal cancer: Evidence for distinct genetic categories based on proximal or distal tumor location. Annals of Internal Medicine 1990;113:779-88.

34 Johnson LR, Christensen J, Jackson MJ, et al. Physiology of the gastrointestinal tract. New York: Raven Press, 1987.

35 Brownson RC, Hoar Zahm S, Chang JC, Blair A. Occupational risk of colon cancer. An analysis by subsite. Am J Epidemiol 1989;130:675-87.

36 Vågerö $D$, Persson G. Occurrence of cancer in socioeconomic groups in Sweden. Scand J Soc Med 1986;14:151-60.

37 Gerhardsson M, Steineck G, Norell SE. Colorectal cancer in Sweden. A descriptive epidemiological study. Acta Oncol 1990;29:855-61.

38 Park RM, Wegman DH, Silverstein MA, Maizlish NA, Mirer FE: Causes of death among workers in a bearing manufactur- ing plant. Am J Ind Med 1988;13:569-80.

39 Vena JE, Sultz HA, Fiedler RC, Barnes RE. Mortality of workers in an automobile engine and parts manufacturing complex. Br J Ind Med 1985;42:85-93.

40 Robinson C, Waxweiler RJ, McCammons CS. Pattern and model makers, proportionate mortality 1972-1978. Am J Ind Med 1980;1:159-65.

41 Ames BN. Dietary carcinogens and anticarcinogens. Oxygen radicals and degenerative diseases. Science 1983;221:1256-64.

42 Hill MJ. Bile acids and human colorectal cancer. In: Vahouny GV, Kritchevsky D, eds. Dietary fiber in health and disease. New York: Plenum Press, 1982.

43 McMichael AJ, Potter JD. Host factors in carcinogenesis: certain bile-acid metabolic profiles that selectively increase the risk of proximal colon cancer. J Natl Cancer Inst 1985;75: 185-92.

Accepted 8 June 1992

\section{Correspondence and editorials}

The British Journal of Industrial Medicine welcomes correspondence relating to any of the material appearing in the journal. Results from preliminary or small scale studies may also be published in the correspondence column if this seems appropriate. Letters should be not more than 500 words in length and contain a minimum of references. Table and figures should be kept to an absolute minimum. Letters are accepted on the understanding that they may be subject to editorial revision and shortening.

The journal now also publishes editorials which are normally specially commissioned. The Editor welcomes suggestions regarding suitable topics; those wishing to submit an editorial, however, should do so only after discussion with the Editor. 